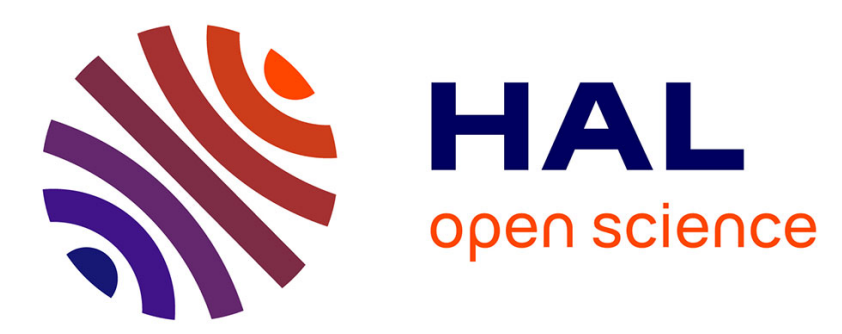

\title{
Pore-scale observation of deposit within the gravel matrix of a vertical flow constructed wetland
}

\author{
Boram Kim, Nicolas Forquet
}

\section{To cite this version:}

Boram Kim, Nicolas Forquet. Pore-scale observation of deposit within the gravel matrix of a vertical flow constructed wetland. Environmental Technology, 2016, 37 (24), pp.3146-3150. 10.1080/09593330.2016.1178334 . hal-02052411

HAL Id: hal-02052411

https://hal.science/hal-02052411

Submitted on 28 Feb 2019

HAL is a multi-disciplinary open access archive for the deposit and dissemination of scientific research documents, whether they are published or not. The documents may come from teaching and research institutions in France or abroad, or from public or private research centers.
L'archive ouverte pluridisciplinaire HAL, est destinée au dépôt et à la diffusion de documents scientifiques de niveau recherche, publiés ou non, émanant des établissements d'enseignement et de recherche français ou étrangers, des laboratoires publics ou privés. 


\title{
Pore-scale observation of deposit within the gravel
}

\section{matrix of a vertical flow constructed wetland.}

\author{
Boram Kim and Nicolas Forquet
}

$\square$ To cite this version:

B. Kim and N. Forquet. «Pore-scale observation of deposit within the gravel matrix of a vertical flow constructed wetland ». Environmental

Technology, v37: 24, pp 3146-3150

DOI:10.1080/09593330.2016.1178334.

Please contact the corresponding author (* nicolas.forquet@irstea.fr) if you are interested by a copy of the article published in the journal. 


\title{
Pore-scale observation of deposit within the gravel matrix of a vertical flow constructed wetland
}

\author{
Boram Kim and Nicolas Forquet ${ }^{*}$ \\ Irstea, UR MALY, 5 rue de la Doua, 69100 Villeurbanne, France \\ * Corresponding author: nicolas.forquet@irstea.fr
}

\begin{abstract}
Lifespan and well-operation of French vertical flow constructed wetlands (VFCW) depend on how the organic deposit forms and evolves within filter media. This study aimed to demonstrate the feasibility of thin section methods application to VFCW. Unfortunately, constructed wetland scientists are currently missing tools to observe how deposit physically occupies pore space. Thin sections allow a direct and undisturbed observation of filter media and deposit. Undisturbed samples were taken from the surface of an experimental VFCW. Water was exchanged with a solvent before resin impregnation to preserve the sample structure. Several thin sections were successfully produced. Results highlight that deposit significantly reduces pore space. It forms a structured media crossed by large channels which can participate to fast gravity-driven flow and media oxygenation. The deposit structure seemed also made of a large bundle of small pores less than $100 \mu \mathrm{m}$ in radius. They can effectively store water by capillarity and provide a large surface for potential pollutant adsorption. Image analysis of thin sections provided hints at understanding the structuration of the porous media linked to organic matter deposition.
\end{abstract}

Keywords: deposit; constructed wetlands; thin section; pore distribution; clogging 


\section{Introduction}

French first stage Vertical Flow Constructed Wetlands (VFCWs) differ from other wetland typologies on granular materials (gravel instead of sand). At the beginning of its operation, raw wastewater flows readily through coarse filter media. However, as time goes by, suspended solids (SS) settle and bacterial biofilm grows within interstitial pore spaces. On the surface, a deposit layer builds up and its structure evolves according to operating (feeding/resting alteration; batch volume, hydraulic and organic loads) and climate (season; rainfall) conditions.[1] Finally plants, micro- and macro-fauna participate to the structuration of both deposit and porous media.[2]

All these phenomena significantly modify VFCW functioning as they age. Aging participates in improving VFCWs performance but may also be responsible of certain VFCW malfunctions. Furthermore, the accumulation of organic matter and its degradation products inevitably lead to clogging.[3] It makes necessary to regularly dredge out the surface deposit layer (every 10-15 years) and clogged porous media beneath on a long term. Therefore, understanding how aging acts on VFCWs may help improving their operation and our perception of their life cycle.

Suspended solid filtration and deposit mineralization are controlled by mechanisms occurring at the pore scale. Only few scientists have tried to observe what is happening within a VFCW $[1,4]$ and even less to look at the pore structure.

The thin section method, which is commonly used in soil science,[5] was chosen for the first direct observation of filter media structure. The objectives of the present work were to (1) evaluate thin section feasibility to VFCW, (2) observe deposit distribution within filter media and (3) quantify its impact on pore size distribution. 


\section{Materials and methods}

\subsection{Sampling and preparation of thin sections}

Sampling was performed in March 2015 from a pilot-scale VFCW located in Irstea's experimental hall at La Feyssine in the metropolitan area of Lyon (France, Figure 1). This experimental setup was meant to simulate granular characteristics of a real-scale first VFCW stage and put in operation since July 2012. From the beginning of its operation, it was fed with real domestic wastewater from a 400.000 p.e. treatment plant. [6] Samples were taken from the surface of the VFCW using Kubiena tins $(l \times \mathrm{w} \times \mathrm{h}$ : $55 \times 75 \times 40$ ). They represented surface gravel layer with thin coat of organic deposit at the top.

In order to remove as much water as possible from the samples before hydrophobic resin impregnation, a solvent exchange in vapor phase was performed to ensure minimal disturbance to samples.[5] Sampled tins were equipped with a perforated lid at the bottom and placed on a raised platform above a bath of acetone. A container of anhydrous calcium chloride was also added to facilitate drying. A 0.79-0.80 range hydrometer was used for water removal monitoring. After several changes of acetone, dried samples (water content $<0.5 \%$ ) were sent to the Stirling University where they were impregnated with polyester (crystic 7449) resin, cut vertically to obtain thin sections (around 30 $\mu \mathrm{m}$ in thickness), polished and coverslipped for protection. 


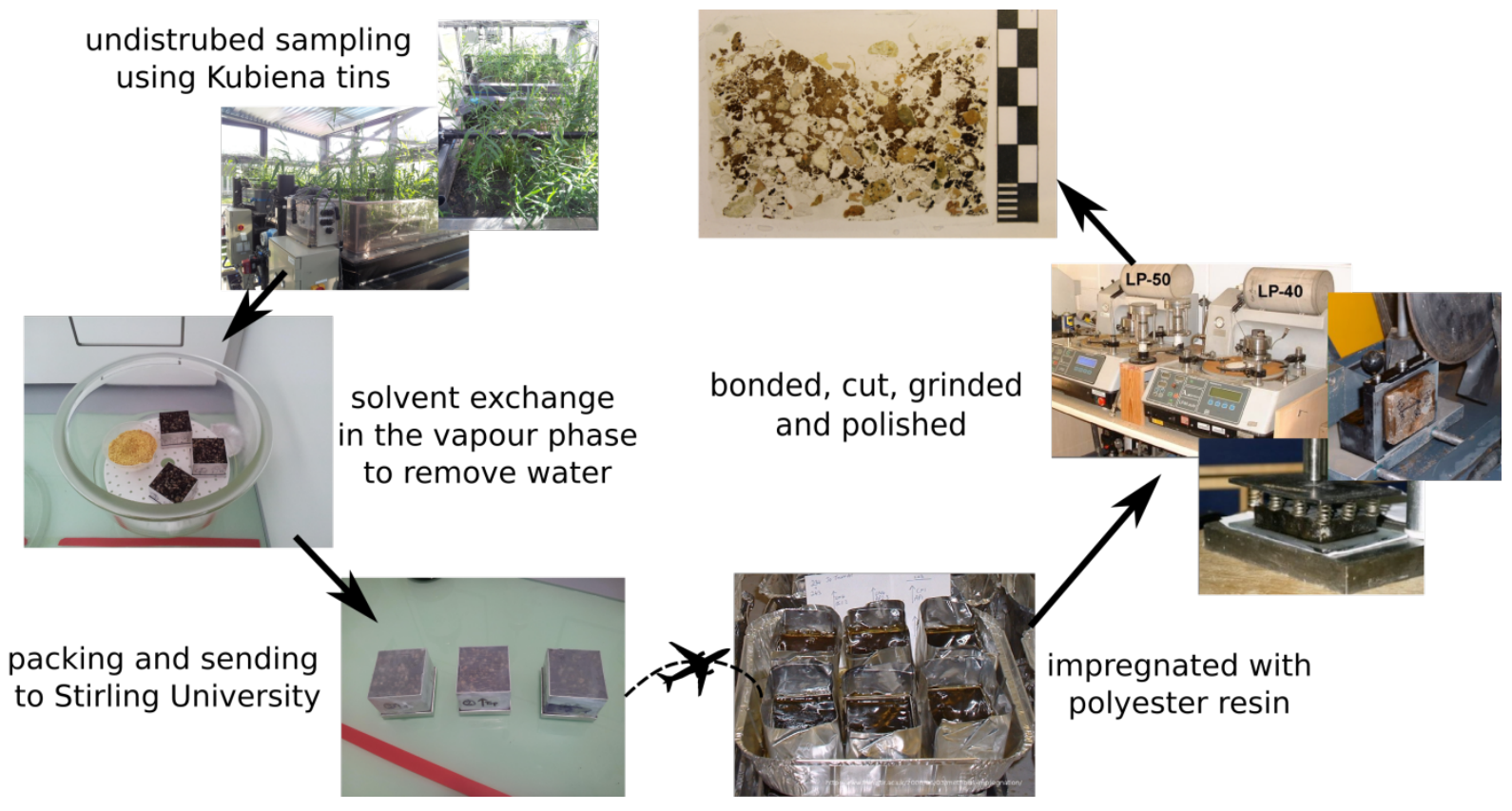

[Figure 1] Sampling and thin section preparation (credits for pictures of sample impregnation and cutting: http://www.thin.stir.ac.uk/)

\subsection{Image acquisition and post-processing}

A stereomicroscope (LEICA MZ16; ×0.71) was used for magnified image acquisition of the prepared thin section. 25 images were taken per thin section. Illumination corrections were individually performed on these images before merging them (Figure 2). Gravels were manually identified using an edge-recognition algorithm (GIMP v2.8.16) and colored in black. A first binary image (Figure 3, a) corresponding to gravel was then extracted. Next, areas corresponding to deposit were distinguished thanks to the low value of their red component. A second binary image (Figure 3, b) was extracted associating gravel and identified deposit areas. 


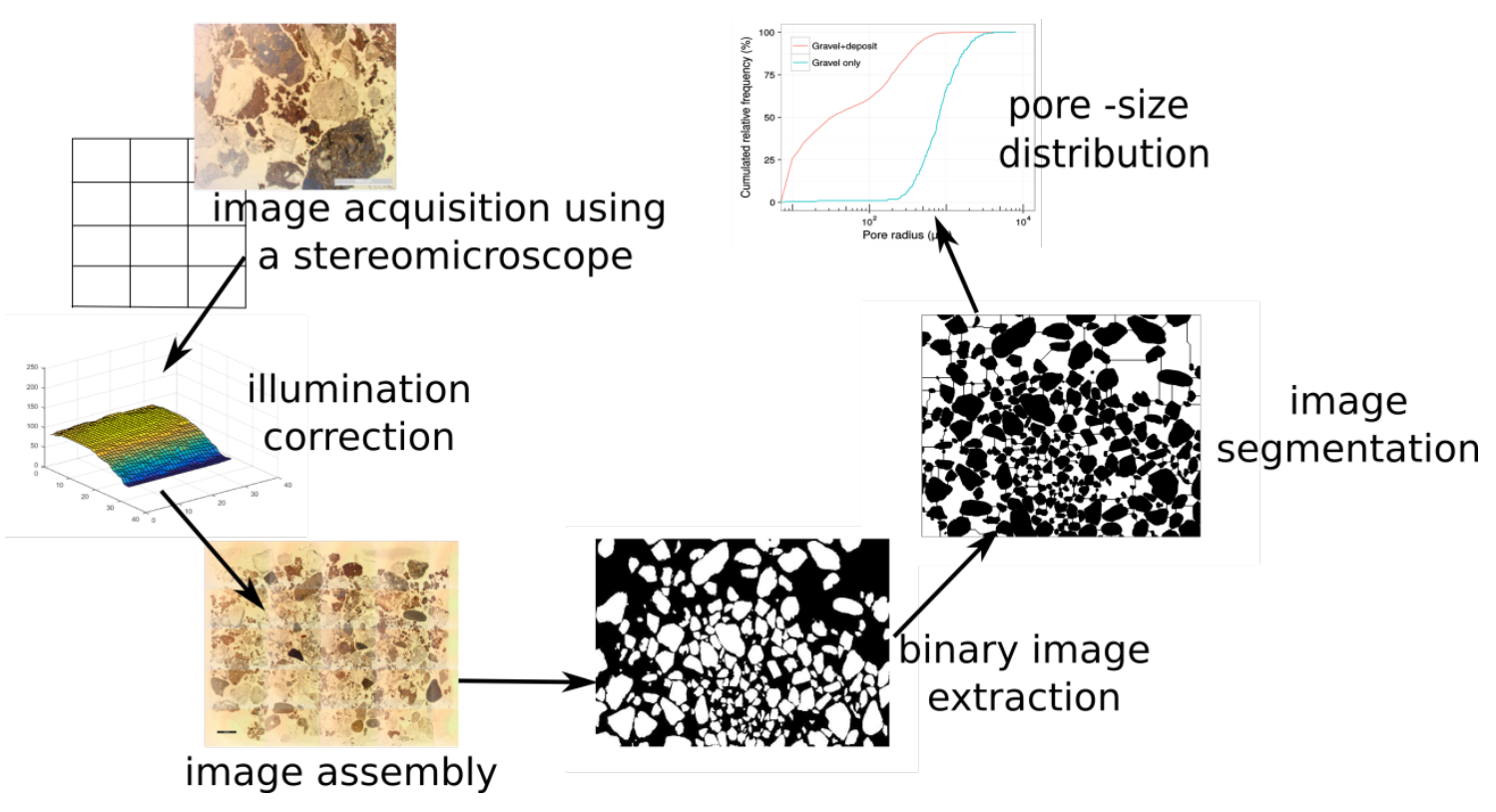

[Figure 2] Post processing.

The following steps were successively applied to those binary images (Figure 3).

(1) Morphological transformations (hole filling for gravels and majority transform for both images) were performed to remove minor roughness without affecting the main part of the structure.[7]

(2) The porosity was estimated by dividing the number of pixels of the pore space by the total number of pixels.

(3) Based on Rabbani et al.,[7] we choose a watershed algorithm for image segmentation.[8] In image processing, the watershed algorithm is analogous to the notion of catchment basin in hydrology. The binary image of the pore space was obtained by taking the opposite of the binary image of gravel or gravel and deposit. Then the opposite of the distance separating each pixel from an edge (the limit between gravel / deposit and pore space) was computed. Minima represent watershed centers, which are analogous to pores.

(4) Pores and throats (constriction between two pores) were identified and labeled.

(5) The surface of each pore was computed and the equivalent radius estimated. Pores were then sorted according to their size and grouped into classes that were used to estimate both their cumulative frequency distribution and the cumulative pore space occupation. The pore space occupation of a class of pore is defined as the total surface of this class of pore divided by the porosity. Image processing was performed using MATLAB (R2013b). 
(a)

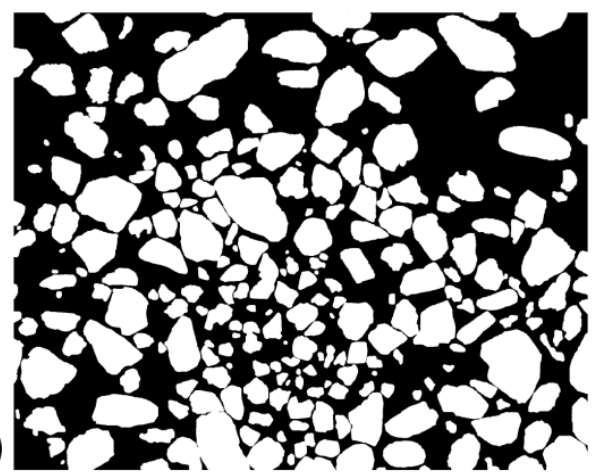

(b)

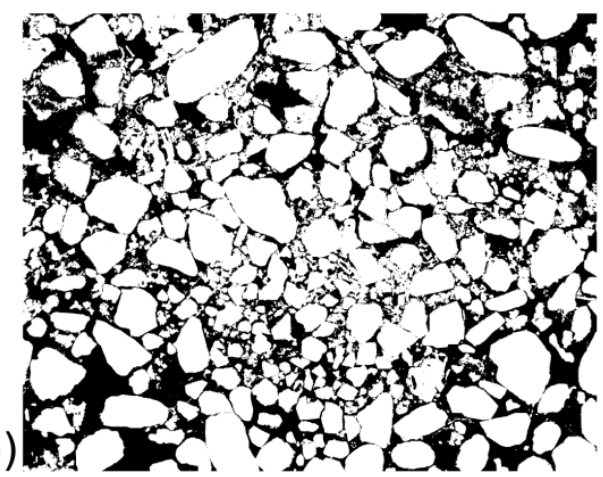

[Figure 3] Binary images of gravel only (left) and gravel and deposit (right). Vertical cross-section of a sample taken from the surface of a VFCW.

\section{Results and discussions}

Three thin sections were successfully produced from samples. G. MacLeod from Stirling University reported that the only difficulty in working with the samples is the combination of both hard lithic material and soft organic material (deposit). This means that grinding to 30 microns has to be done very carefully to avoid loss of the deposit. Hereafter we choose to only focus on results obtained from one thin section since they are similar for all three thin sections.

\subsection{Visual observation of thin sections}

Direct observations of the thin section (Figure 4) clearly highlight the migration of organic deposit in depth confirming its space occupation within filter media. Nevertheless, deposit is not forming a coat on gravel surface. It forms an organic matrix within the pore space bounded to gravel at some location and structured by large channels (reaching 382 and $421 \mu \mathrm{m}$; Figure 4), providing macro-pores for preferential gravitational flows. The formation of these channels cannot be due to the sample drying 
process since the water / acetone exchange in vapor phase cannot cause shrinkage or cracking of deposit in such scale.[5] Creations of those channels may be therefore elucidated by the combination of deposit remobilization by flow, mineralization and cracking during rest periods. These large channels may also ease the oxygen penetration within the filtration layer despite the significant decrease of the porosity (from 0.51 to 0.33). For comparison, Morvannou et al. [9] measured the porosity of clean filter material and filter material with deposit in a French VFCW. The values are 0.44 and 0.406, respectively.
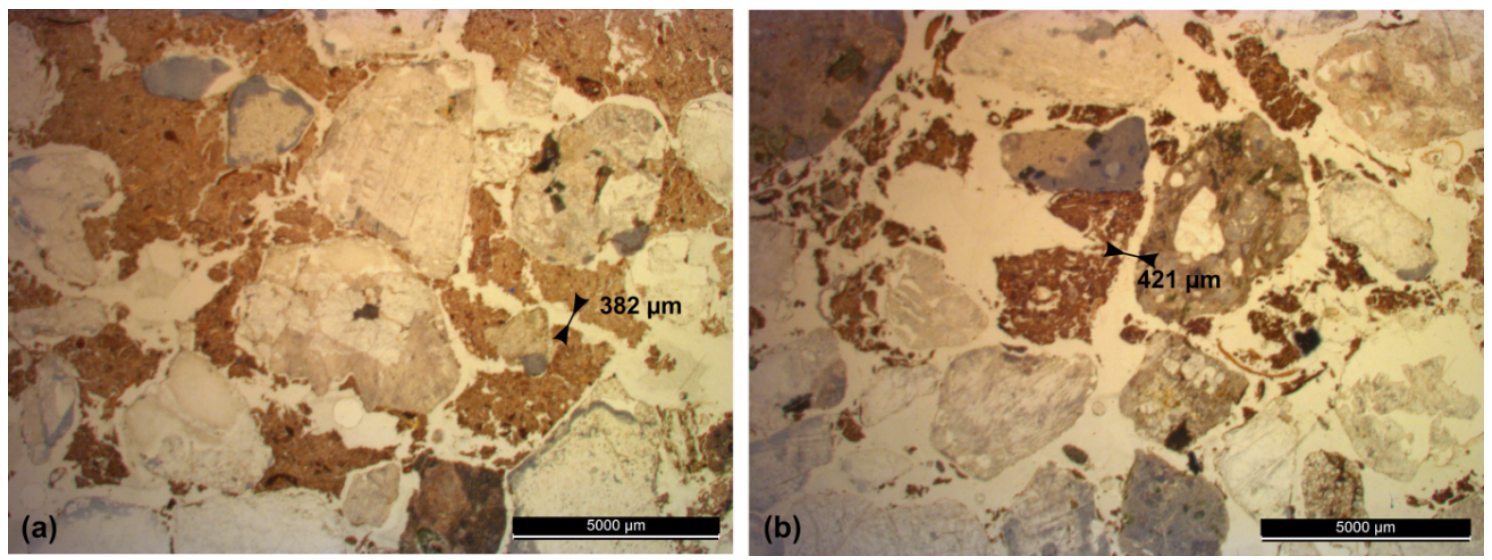

[Figure 4] Magnified images of thin sections of VFCW filtering materials.

Figure 3 displays the binary images of gravel only and gravel and deposit. On image (a), gravels seem coarser on the upper part of the sample. We recall that samples were taken from surface. Therefore we can assume that some segregation took place at the surface and that finer grains were transported deeper.

\subsection{Pore-size distribution analyses}

Segmentation aims at separating the pores. The result of segmentation for gravel only is shown on Figure 5. The watershed algorithm is known for its tendency to over-segment. 
We filtered out the smallest minima to limit the number of watershed and consequently the number of pore. Once a satisfying segmentation was reached, we estimated both the cumulative frequency distribution and the cumulative pore space occupation (Figure 6). The presence of deposit transforms water path networks in two manners: i) general reduction of pore size and ii) creation of micro-scale pores.

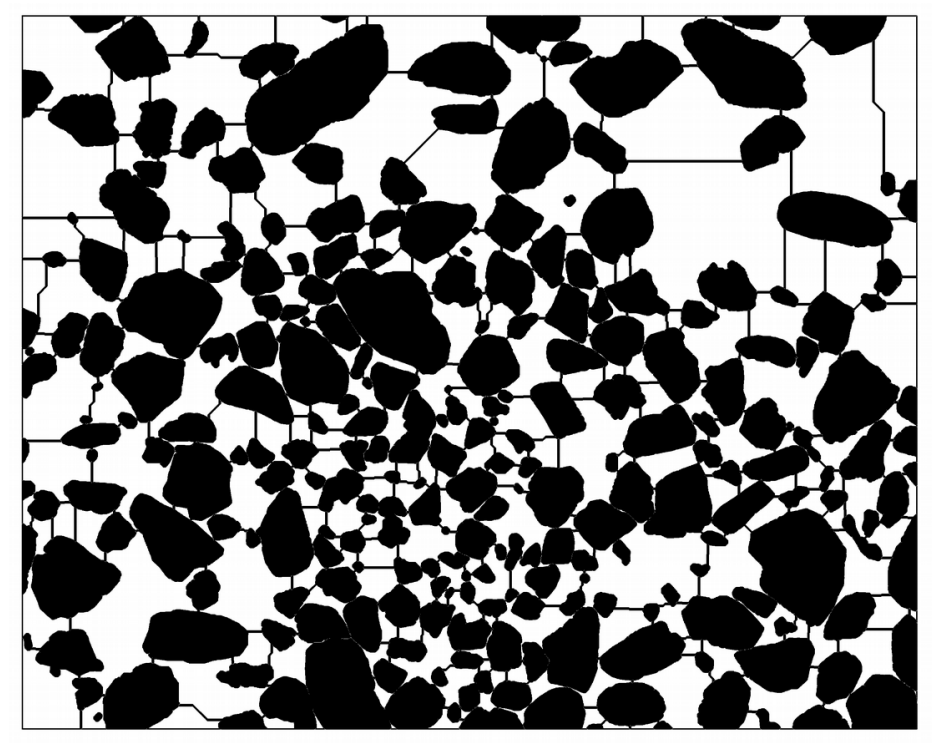

[Figure 5] Segmentation results for gravel only. Vertical cross-section of a sample taken from the surface of a VFCW.

Flow in a gravel media is mainly driven by gravity and little water is kept by capillarity. The presence of deposit seems to change this behavior. Figure 6 a) shows a bimodal distribution for gravel with deposit. The lower mode includes pores ranging from 0 to $100 \mu \mathrm{m}$. It includes $61 \%$ of all pores but represents only $10 \%$ of the pore space. Water can be hold by capillarity in those pores where it moves slowly while larger pores remain available for fast gravity-driven flow. It corroborates assumptions made by Morvannou et al. [9] who used a dual-porosity model to accurately represent tracer movement in VFCW. 

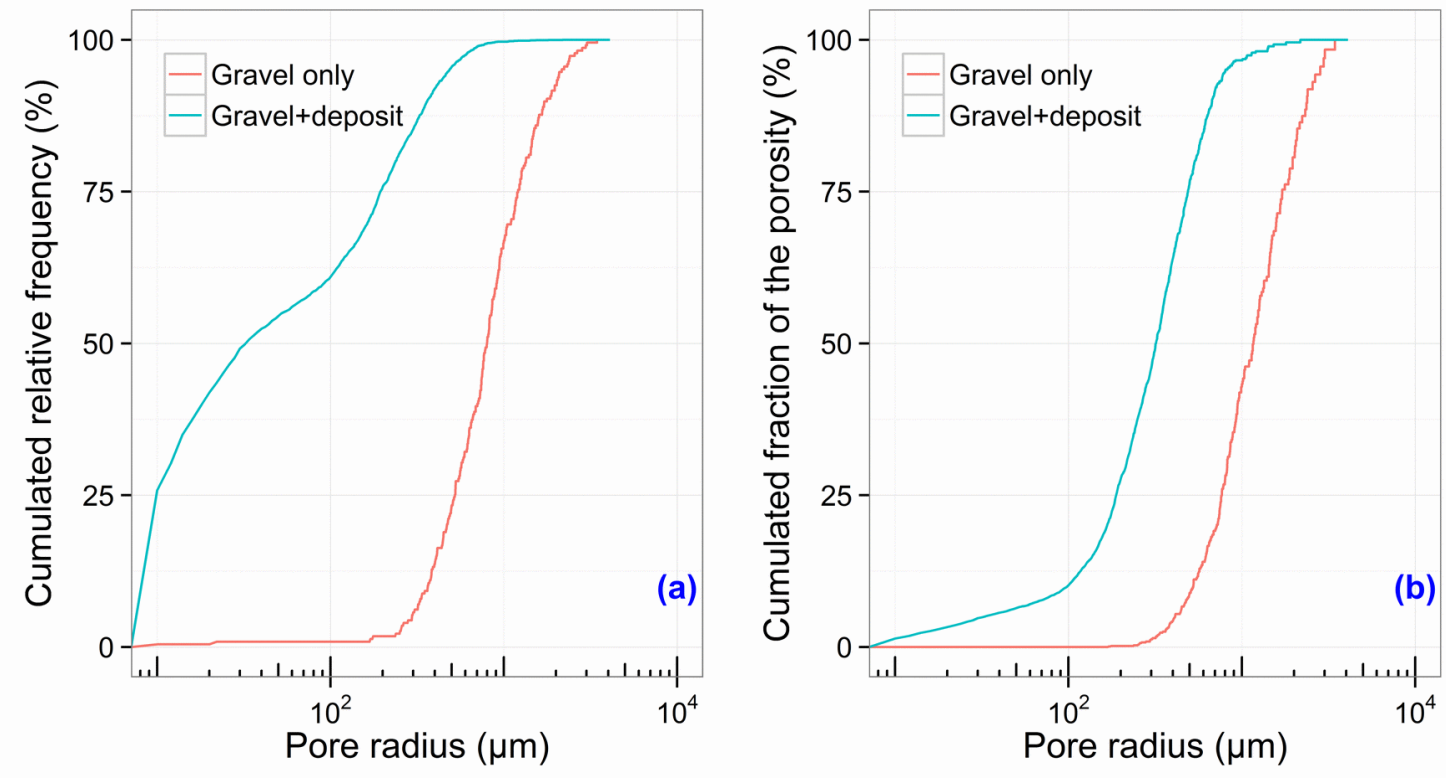

[Figure 6] Comparison of cumulative pore size frequency distributions (a) and cumulative pore space occupations (b) between gravel only and gravel with deposit.

The network of micro-scale pores increases the interaction surface between water (containing pollutant, like ammonium, trace elements) and organic matter that provides potential sites of adsorption. It supports results showing high retention capacity for ammonium in VFCW fed with raw wastewater.[10]

\section{3. $\quad$ Limitations}

The chosen method of image acquisition limits the resolution to $6.8 \mu \mathrm{m}$ pixel $^{-1}$. Smaller pore structure cannot be observed. However, the observation at smaller scale might not have been worthful. The drying process may have caused cracks at similar scale that could bias interpretation.

Individual thin section provides a 2D representation of the pore structure that improves our understanding of deposit influence on water flow and pollutant transport. 
A necessary further step will be the investigation on the spatial structure of deposit (3D observation). It could be achieved by using multiple parallel slices of the same sample or by X-ray tomography.[11]

\section{Conclusions}

The presented work demonstrated the feasibility of the thin section method application to French VFCWs filter media observation. This method allows a direct and undisturbed observation of pore structure.

Results highlight that deposit significantly reduces pore space (porosity is reduced by 35\%). Direct observation showed that deposit is not only attached to gravel but forms a granulated structure with large pores running through the assemblage of gravel and deposit. Numerical pore size distribution analyses pointed out that the deposit structure is made of a large bundle of small pores less than $100 \mu \mathrm{m}$ in radius.

Image analysis of thin sections provides hints at understanding the structuration of the porous media linked to organic matter deposition. This is of critical importance when studying how water is stored and flows through the porous media. These promising results encourage us to continue in order to observe the three dimensional structuration.

\section{Acknowledgements,}

The authors wish to thank Georg MacLeod from University of Stirling for resin impregnation and cutting thin sections of samples. The authors would also like to thanks Claire Bertrand, Jérémie Aubert, Clément Crétollier and Adeline François for their technical support.

\section{References:}


[1] Molle P. French vertical flow constructed wetlands: a need of a better understanding of the role of the deposit layer. Water Sci Technol. 2014;69:106112.

[2] Vergeles Y, Butenko N, Ishchenko A, et al. Formation and properties of sediments in constructed wetlands for treatment of domestic wastewater. Urban Water J. 2016;13:293-301.

[3] Nivala J, Knowles P, Dotro G, et al. Clogging in subsurface-flow treatment wetlands: Measurement, modeling and management. Water Res. 2012;46:16251640.

[4] Hua G F, Zhu W, Shen J Q, et al. The Role of Biofilm in Clogging Process in Vertical Flow Constructed Wetland. Appl Eng Agric. 2013;29:61-66.

[5] Camuti K S, McGuire P T. Preparation of polished thin sections from poorly consolidated regolith and sediment materials. Sediment Geol. 1999;128:171178.

[6] Silveira D D, Belli Filho P, Philippi L S, et al. Influence of partial saturation on total nitrogen removal in a single-stage French constructed wetland treating raw domestic wastewater. Ecol Eng. 2015;77:257-264.

[7] Rabbani A, Jamshidi S, Salehi S. An automated simple algorithm for realistic pore network extraction from micro-tomography images. J Petrol Sci Eng. 2014;123:164-171.

[8] Meyer F. Topographic distance and watershed lines. Signal Process. 1994;38:113-125.

[9] Morvannou A, Forquet N, Vanclooster M, et al. Which hydraulic model to use for vertical flow constructed wetlands? In: Simunek J. 4th International Conference HYDRUS Software Applications to Subsurface Flow and Contaminant Transport Problems. Proceedings; 2013 Mar.; Prague. Czech Republic. 2013.

[10] Morvannou A, Choubert J-M, Vanclooster M, et al. Modeling nitrogen removal in a vertical flow constructed wetland treating directly domestic wastewater. Ecol Eng. 2014;70:379-386.

[11] Blunt M, Bijeljic B, Dong $\mathrm{H}$, et al. Pore-scale imaging and modelling. Adv Water Resour, 2013;51:197-216. 